\title{
Innovative Training Based on Dance Consciousness in College Dance Teaching
}

\author{
XIANG Yanhua ${ }^{1, a}$ \\ ${ }^{1}$ Dance Institute, Yunnan Arts University, Kunming 650000,China \\ axiangyanhuayn@163.com
}

Keywords: dancing tutorial, Dance awareness, cultivation

\begin{abstract}
The dance teaching in college is mainly composed of the teaching of music and the teaching of education. The dance awareness of dance students is relatively weak. However, the dance awareness in dance teaching is very important. For example, in dance teaching, Dance awareness to enable students to better use the body to perceive the rhythm of music in order to better understand the essence and content of its dance. Only the formation of dance awareness in dance learning can better understand the meaning and value of dance. In the process of human development, consciousness belongs to the human brain and people feel their own existence through thinking. Dance awareness can better show the existence of dance. The perception of dancing can be understood as combining body and soul in dancing.

Through the knowledge of dance as well as the understanding of ideas and ideas, better understand the deep meaning of dance. For this reason, the dance awareness in dance teaching is of crucial significance, and it is necessary to pay attention to the cultivation of dance awareness. With the introduction of the concept of new curriculum education, all colleges and universities are constantly trying to reform in education and teaching in order to achieve better teaching results. In the university dance teaching, not only need students to master the most basic dance knowledge and skills, but also to enable students to understand the dance awareness of dance learning, dance learning in the grasp of dance awareness can be said to master the spirit of dance. Dance awareness in college dance teaching is of great significance to them. To this end in the dance teaching should pay attention to the training of students in dance awareness in order to allow students to better understand the charm of dance and achieve better learning results of the dance. This article focuses on the training of students in the dance of dance awareness in order to achieve better education and teaching effectiveness.
\end{abstract}

\section{Relationship between dance and performance}

There are various performances in real life, such as dance, music, drama, folk art, acrobatics, magic, comic dialogue and so on. Among them, dance is one of the performing arts and one of the performing arts. Dance is an ephemeral art, in which the dancer expresses his inner feelings in an effective time. The dancer communicates the emotions he wants to express to his audience through exquisite dancing skills and rich body language. Aroused the audience's resonance, so that dance in the audience's mind left a deep impression.

Dance and performance are both art, dance and performance are complementary and mutually reinforcing. Dance is inseparable from the performance of dance through performance to express emotion, through the performance of the dance will show the content and charm, out of the performance of the dance lack of contagious and agile, it will become lifeless, like a There is no soul body, at the same time, the performance is inseparable from the dance, dance is a representative performing arts, the advent of dance not only adds to the vitality of the performing arts, but also enriched the form of performing arts, performance through dance to be expressed Thought and feelings and good wishes for life are presented to the audience.

There is a cross-relationship between dance and performance. Some qualities of dance are 
pursued. Performances are also pursued. Some of the content involved in dance is also covered in performance. For example, dancers in addition to dance to show rich, superb skills, but also through the rich expression of the dancer and body movements to reflect the character's emotions, anger, sadness, music and other emotions and character traits, Performing actors need to show their emotions and personality traits when performing.

\section{Dance Cognitive Consciousness Training in Dance Teaching}

What dance is exactly is a question that beginners think when they first started. Dance is a kind of art. More is derived from life. It is an art sublimated from life, mainly through a certain rhythm art. Usually with the help of music and some other tools for dance expression. Dance itself has a variety of meanings, can be used to exercise, etiquette and so on. However, it is more understandable that the contents of the dance should be able to understand the dance culture and the feelings contained in the dance. Dance culture is more able to express the deep connotation of the dance, learners understand the dance culture, in order to better understand the charm of dance, into the dance learning, master the dance skills, to achieve better learning effect of the dance.

The dance is usually expressed by means of body movements. The dance movement is a language expressed as a dance art and a silent performance art expressing the dance. It generally has the characteristics of personalization, visualization and emotionalization.

Dance language generally meet certain aesthetic standards, so as to be able to better perform the art of expression. For example, when studying ballet dance, the requirements on body posture are generally open, stretched, straight, and standing. "Open" means that all joints such as shoulder and chest can be opened during the dance process, Itself gives the feeling is relatively tall and straight, showing the feeling of freedom and unrestrained, but also to reflect the elegance of the dancers temperament[1]. Dance pays attention to certain orientation. The awareness of space and time in dance is the most basic quality of a dancer in the dance process. It is the most basic teaching content for students to master their space-time orientation in dance teaching. Dance general body in the space for expression, therefore, in the dance teaching must first have a clear understanding of the spatial orientation. In the dance teaching, students can perceive the air in the air and let them imagine as the objects that can be seen. The actions drawn in the air will leave clear traces. In the dance teaching, students can be better Perception, so that students in the dance process to experience the relationship between arms and space in order to better dance learning.

Dance is the expression of the most emotional expression of the most substantial and the most simple form of expression, is a composite of other arts. The essence of dance is life, emotion, beauty, which is also the eternal theme of dance in expression[2]. People's creation of dance comes from the needs of people's internal spirits, and can express emotions better in dancing. In the dance expression to be able to broaden their artistic space, the teaching methods continue to enrich, so that students in the process of learning to dance constantly improve their aesthetic ability in order to better enhance students' interest in dance.

\section{Cultivation of Awareness of Action in Dance Consciousness}

Beginners in dance learning generally follow the teacher's movements to imitate, usually starting from the simplest movement, starting from the facial features, from the pendulum to the most basic form of movement began to allow students to experience limbs, through Body movements to remember dance moves. In dance teaching, the most important thing is to cultivate students 'awareness of movement, in order to better enhance students' ability of body coordination, and can make the movement of the body get some training. In the dance teaching first let students master the most basic body posture gestures, and then from the inside out to learn the basic movements of dance[3]. Dance beginners generally do not pay attention to the physical aspects of the 
consciousness of learning to dance during the rise, etc., but this body awareness is very difficult for beginners to develop, beginners in the dance are usually subconscious bow.

In dance teaching, in order to better cultivate students' dance awareness, the following methods can be used: to allow students to try sleeping without sleep pillow, lying flat sleeping position, so that the whole body can be in a straight state. In addition, the rest should also allow students in the upright state, so that students can develop tall and straight posture, on the other hand do not delay the students' knowledge to achieve better results. It also allows students to watch their movements in the mirror as they dance, in order to promptly detect non-standard movements for timely correction so that students can avoid bowing habits. In this way, students develop good habits in order to achieve better results.

\section{Understanding of Breath and Strength}

Dance in the atmosphere refers to the rhythm in the dance as well as expressions, etc., students in the dance process can be opened to each joint, the rhythm of the dance experience. In addition, we should also be able to appreciate the intensity of the dance. The intensity of the dance is the use of qi in the dance so as to keep the atmosphere comfortable[4]. The physical training in the dance teaching is the beginning of the performance of the dance art in the teaching process. Through the training of students in the dance, students can form a certain expressive artistic feeling. For example, in the classical dance, qi exercises and body are combined, through such actions can make students feel better dance charm, and achieved good results. In the performance of the dance, when it is a sad atmosphere, it is usually a long sigh, more happy when you breathe. The cadence in body movements in the dance is controlled by the gas in order to better show the charm of the dance.

\section{Cultivation of Psychological Consciousness in Dance Consciousness}

In dance teaching, there is not only an external action but also an emotional dominance. There is no point in the dance without emotion. In the dance expression, emotion is the unity of the mind and the body. In the dance teaching can let students practice some happy or sad action, by allowing students to simulate some visualized body movements in the study, in order to better the performance of the dance body movements[5]. In dance teaching, students should first imitate some body movements and find the expression of emotion from these movements. In the actual dance practice should be able to better express the expression of the body from the emotional expression. People in the expression of body movements, the space will be subject to restrictions, but the student's psychological space is unrestricted, only in dance teaching so that students can be psychologically widened in order to be able to physically expand.

Dance is a way to express the beauty of the human body. Dance is not only external beauty, but also manifests the inner beauty. Cultivating students 'aesthetic awareness of dance generally should cultivate the students' ability to feel the beauty and appreciate the beauty. In the process of creation, dance art generally refined the beauty and emphasized a certain degree of rhythm. Dance performance means generally through the dance of the movement process and the corresponding mood, the dance is mainly through the audience to set an imagined space for the audience to imagine in order to obtain the feeling of beauty. In dance teaching, students not only learn the corresponding external beauty, the most important thing is to enable students to feel the inner beauty of dance and better understand the charm of dance.

Dance is an art used to express emotions. Imagination is the wings of a dance. Only the rich imagination in a dance piece can create an engaging dance piece. In the artistic creation can not do without imagination. In dance teaching, teachers should be able to encourage students to exert their own imagination in the dance, do not be afraid of mistakes. Long time practice has proved that when students feel that they are respected by teachers during their studies, students will take the initiative to participate in the study of dance and achieve better results. They will also exert their 
own imagination in the study of dance so as to make it more Good understanding of the charm of dance. In addition, as students' self-confidence in dancing continues to increase, students will show their enthusiasm for dancing in their dances and actively participate in the learning of dances in order to achieve better learning outcomes. Students experience the joy of learning dance in their dance learning and actively participate in the learning of dance in order to understand the charm of dance. In dance learning, only innovation can better understand the charm of dance and achieve better dance results.

\section{Enhance the Appeal of Dancing}

The dance is mainly a silent art in which performers express and express their inner thoughts and emotions through body language. Performers express their emotions and performance through the exchange of body movements and facial expressions of dance with themselves and their audiences My most perfect side. In addition, dancers will also use clothing to attract the attention of the audience, using an optimistic and cheerful attitude to mobilize the enthusiasm of the audience. Such as "river drifting water" dance, this dance is about the moon came out, in the long mountain, Qingyin the streams and the breeze was blowing, the hero and heroine by singing a cheerful love songs tell their own love of Acacia. During the performance, the costumes used by the dancers reflect the background of the dance. At the same time, the dancers reflect the sweet love between the hero and the hero in the dance through gentle movements, superb dance skills and cheerful pleasures, Good wishes of love convey to the audience, infect the audience. Therefore, the dance performance can not only show the content of the dance, but also stimulate the attention of the emotion, so as to arouse the resonance of the dance performer and the concerned emotion.

\section{Increase the Flexibility of the Dance}

Performance can increase the agility of the dance. Dancers in the dance by adding a beautiful show, can make dance vivid, dancers perform like a wizard, which is mainly the dancers will dance the flexibility of the perfect show, memorable [3]. For example, Yang Liping, an outstanding dancer in our country, once presented the spiritual beauty of peacock dance perfectly to the audience's eyes and has remembered vividly so far.

\section{Increase the Artistic Conception of Dance}

Each dance has a certain creative background, reflecting a mood. Performance can help dancers reflect the mood of dance, thereby enhancing the sense of the picture of the dance and the audience's imagination. The performance into the dance among them, easy to make the idea of imagination, outline the beautiful mood. Public like the "Pteris-tail bamboo" moonlight dance, in this dance, dancers wearing Dai costumes, with graceful light dance and rich facial expressions to show the artistic conception of this dance at a glance.

\section{Conclusion}

In college dance teaching, not only should students learn the appropriate dance knowledge, but also enable students to understand the charm of dance and achieve better learning results. In the study of dance, the awareness of dance is of crucial significance. Through the cultivation of students' dance awareness, students can better understand the meaning of dance and achieve better dance results. Therefore, in the university dance teaching should pay attention to the training of students' dance awareness. The training of awareness of dance: Dance itself has a variety of meanings, can be used to exercise, etiquette and so on. But for the content of dance, but also should understand the dance culture and the feelings contained in the dance. Dance pays attention to a certain orientation. The awareness of space and time in dance is the most basic quality of a dancer in the process of dancing. It is the most basic teaching content for students to master their space- 
time orientation in dance teaching, as well as the cultivation of the emotion awareness of dance. Focus on the awareness of dance awareness training: physical control and body awareness, so that students in peacetime learning and practice can focus on the training of body awareness. In addition, we must be able to recognize the importance of breath and strength. In dance teaching, we should pay more attention to the cultivation of psychological consciousness, and we should be able to express the body better in the dance practice from the expression of emotion.

In the dance teaching, not only students can learn the corresponding external beauty, the most important thing is to enable the students to feel the inner beauty of the dance and better understand the charm of the dance. To enable students to experience the dance in the learning of the charm of the dance, so that students take the initiative to participate in the dance learning, awareness of dance to achieve better learning effects of the dance.

\section{References}

[1] Qiwang Zhang.Innovative Training Based on Dance Consciousness in College Dance Teaching[J]. Theater House,2016,(06):188.

[2] Lixiong Gao.On the Cultivation of Students 'Dance Consciousness in High Teacher' s Dance Teaching[J]. Popular literature and art,2011,(16):240-241.

[3] Huan Cao. Talking about the Training of Students' Innovative Dancing in Higher Vocational Colleges[J]. The sound of the Yellow River,2011,(15):92-93.

[4] Yan Feng. Research on Aerobics Dancing Teaching and Cultivating College Students' Innovative Ability[J]. Youth sports,2013,(01):106-108.

[5] Yinying Wang. On the Training of Dance Expression in High Teacher 's Dance Teaching[J].Art sea,2012,(10):132-135. 